\title{
Bioengineered self-seeding heart valves
}

\author{
James E. Jordan, PhD, ${ }^{\text {a }}$ J. Koudy Williams, DVM, ${ }^{\mathrm{b}}$ Sang-Jin Lee, PhD, ${ }^{\mathrm{b}}$ Devanathan Raghavan, PhD, ${ }^{\mathrm{b}}$ \\ Anthony Atala, MD, ${ }^{\mathrm{b}}$ and James J. Yoo, MD, $\mathrm{PhD}^{\mathrm{b}}$
}

Objective: Mechanical and biological prostheses are used to replace damaged heart valves but are associated with significant morbidities. Although there is increased interest in bioengineering cell-seeded heart valve scaffolds, it is a time-consuming and technically difficult process. The goal of this project was to engineer selfseeding heart valves that mature quickly in vivo and have a shorter preparation time.

\begin{abstract}
Methods: Porcine pulmonary valves were decellularized using detergent methods and then either (1) left untreated (unconjugated, $n=6$ ), (2) reseeded with autologous endothelial progenitor cell-derived endothelial cells (cell-seeded, $\mathrm{n}=4$ ), or (3) conjugated with CD133 antibodies (conjugated, $\mathrm{n}=8$ ). The valve constructs were transplanted into the pulmonary position of sheep using standard surgical techniques. After 1 or 3 months, the implants were removed and assessed for cell and matrix content as well as biomechanical properties.
\end{abstract}

Results: Endothelial cells expressing von Willebrand factor lined the entire length of both ventricular and arterial surfaces of conjugated valves by 1 month after implantation. Interstitial cell and structural protein content of conjugated valves increased from 1 month to 3 months with interstitial expression of metalloproteinase- 9 and new collagen formation. In contrast, there were few endothelial or interstitial cells associated with unconjugated, or cell-seeded valves at any time point. No calcification or thrombi were noted on any of the valves. Young's modulus and tensile strength was greater in the conjugated valves versus unconjugated or cell-seeded valves.

Conclusions: Results indicate that tissue-engineered heart valve replacement constructs can be made quickly and therefore may be a clinically relevant option for patients needing heart valve surgery in a timely fashion. (J Thorac Cardiovasc Surg 2012;143:201-8)

Valvular heart disease is a common diagnosis worldwide, with many of these patients eventually needing an operative intervention. From 1998 to 2005, approximately 300,000 valve replacement operations were performed in the United States alone. ${ }^{1}$ Whereas valve replacement surgery has evolved since the early 1950s, when it was first described as an experimental procedure in $\operatorname{dogs}{ }^{2}$ major clinical advances in valve replacement constructs have lagged. There still exist only 2 basic alternatives, mechanical and biological prostheses, both of which have significant limitations. Serious complications arising from all types of valve replacements run about $2 \%$ to $4 \%$ and include thromboembolism, size mismatch, endocarditis, mechanical dysfunction, and hemolysis. ${ }^{3} \mathrm{Me}-$ chanical valves have a functional life span of at least 25

\footnotetext{
From the Department of Cardiothoracic Surgery ${ }^{\mathrm{a}}$ and the Wake Forest Institute for Regenerative Medicine ${ }^{\mathrm{b}}$ Wake Forest School of Medicine, Winston-Salem, NC. Funded in part by a grant from the Errett Fisher Foundation.

Disclosures: Authors have nothing to disclose with regard to commercial support.

Read at the 37th Annual Meeting of The Western Thoracic Surgical Association,

Colorado Springs, Colorado, June 22-25, 2010.

Received for publication June 20, 2011; revisions received Sept 14, 2011; accepted

for publication Oct 3, 2011; available ahead of print Nov 3, 2011.

Address for reprints: J. Koudy Williams, DVM, Wake Forest Institute for Regenera-

tive Medicine, Wake Forest University Health Sciences, 391 Medical Center Blvd,

Winston-Salem, NC 27101 (E-mail: kwilliam@wakehealt.edu).

$0022-5223 / \$ 36.00$

Copyright (C) 2012 by The American Association for Thoracic Surgery

doi:10.1016/j.jtcvs.2011.10.005
}

years but are associated with life-long anticoagulation treatment and the concomitant risk of thromboembolism and bleeding. ${ }^{4}$ Bioprostheses generally have better hemodynamic characteristics and avoid long-term anticoagulation therapies but are associated with progressive tissue deterioration. ${ }^{5}$ Furthermore, all commercially available tissue valve substitutes are nonviable with minimal potential to grow, repair, or remodel. Therefore, their clinical utility is limited, especially in growing children. ${ }^{6,7}$ These limitations tend to guide surgeons in choosing a replacement construct to match the patient's age and lifestyle. Living tissue replacements with the capacity for growth and regeneration provide fundamental advantages over the currently available cardiovascular replacements.

Tissue-engineering techniques may play a prominent future role in the development of heart valve replacement therapy. The principal goal of tissue-engineered heart valve (TEHV) construction is to create living tissue that, in response to repeated applications of complex shear forces and bending stress, heals and regenerates instead of becoming calcified or developing other structural abnormalities. The ideal prosthetic valve would have the following characteristics: (1) widely available "off the shelf"; (2) normal hemodynamic performance; (3) low risk for thromboembolism, endocarditis, calcification, and/or degeneration; and (4) ability to grow and self-repair. Tissue-engineering 


\section{Abbreviations and Acronyms \\ $\mathrm{ECM}=$ extracellular matrix \\ $\mathrm{EPC}=$ endothelial progenitor cell \\ MMP-9 = matrix metalloproteinase-9 \\ GAG = glycosaminoglycans \\ TEHV $=$ tissue-engineered heart valve}

techniques provide an opportunity to provide significant improvements in valve replacement technology.

An early TEHV was the Synergraft decellularized homograft prosthesis (CryoLife Inc, Kennesaw, Ga). It was thought that host cells would repopulate the decellularized scaffold and provide the functions of a living valve: growing, healing, resistance to infection, and creation of an extracellular matrix (ECM). Although histologic studies demonstrated recipient cells within these grafts, ${ }^{8}$ the functionality of these cells is unclear as evidenced by some early degeneration. ${ }^{9}$ These findings suggest that providing only a scaffold for passive in vivo seeding will likely not suffice in the long-term.

More recent laboratory efforts have focused on identifying appropriate scaffold materials, progenitor cell sources, and seeding/conditioning techniques. TEHV grown from autologous cells seeded on biodegradable synthetic polymers and matured in vitro have functioned in the pulmonary circulation of growing lambs for up to 5 months. ${ }^{10}$ However, this involves the time-consuming task of isolating and culturing cells before adding them to a valve construct and then conditioning the resulting construct in vitro, a process that can take many weeks or even months. In this proofof-concept study, we hypothesize that in vitro conjugation of decellularized pulmonary valve constructs with CD133 antibodies promotes rapid in situ self-seeding, remodeling, and maturation of normal heart valve structure and cell function.

\section{MATERIALS AND METHODS Animal Studies}

Studies were performed in accordance with the "Guide for the Care and Use of Laboratory Animals" (1996) published by the National Institutes of Health under a protocol approved by the Wake Forest School of Medicine Animal Care and Use Committee.

\section{Experimental Design}

Female sheep (35-65 kg) were randomized to receive 1 of 3 types of valve constructs, all of which were based on a decellularized porcine pulmonary valve. The 3 groups were as follows: (1) unconjugated $(n=6)$; (2) cell-seeded $(n=4)$; and (3) conjugated $(n=8)$. Unconjugated valves were decellularized porcine valves with no additional treatment. Cell-seeded valves were decellularized valves that were seeded with autologous endothelial cells 1 week before implantation. Conjugated valves were decellularized valves that underwent a protocol to attach an antibody that recognized sheep CD133, an endothelial progenitor cell (EPC) marker.

\section{Decellularization Protocol}

Decellularized constructs were prepared from porcine pulmonary valves isolated as previously described. ${ }^{11}$ The pulmonary valve was dissected from the heart, leaving 2-cm margins on each side of the annulus. The constructs were then decellularized using water lysis and treatment with Triton X-100 (Dow Chemical Company, Midland, Mich) and ammonium hydroxide. The constructs were washed thoroughly before glutaraldehyde fixation and sterilization by gamma irradiation.

\section{Cell Collection}

EPCs were isolated from sheep using a technique similar to that previously described. ${ }^{12}$ In brief, an arteriovenous shunt was established using the femoral vessels into which a sterile stem cell purification cartridge (CD133 antibody bound to sepharose beads) was placed. After the column was removed from the circulation, the beads were removed from each column and rinsed over mesh filters to remove unbound cells. Cells were passed through a new mesh strainer to remove the beads, pelleted by centrifugation, and resuspended in endothelial cell growth media 2 (EGM-2; Cambrex, East Rutherford, NJ).

\section{Cell Culture/Seeding and Construct Conditioning}

Cells were cultured with endothelial cell growth media 2 for 24 hours before the unattached cells were transferred to fibronectin-coated culture plates and differentiated until cells with endothelial morphologic characteristics were visible and proliferating. Cultures were split at $70 \%$ confluence until $2 \times 10^{6}$ cells were obtained, usually by the fourth passage. Endothelial cells $\left(1.5 \times 10^{6}\right.$ cells $/ \mathrm{mL}$ in Dulbecco modified Eagle medium $)$ were seeded onto the valve matrix systematically to distribute them as evenly as possible. Cells were seeded on a small area (ie, ventricular surface of a leaflet) and allowed to attach before rotating the valve construct and seeding the next area. This process continued until the entire surface had been covered.

After the seeding process, the constructs were cultured for 7 days before being conditioned in a computer-assisted, flow-dependent bioreactor system, as previously described. ${ }^{11}$ Flow and pressure were monitored to ensure that physiologic conditions were maintained throughout conditioning. After the scaffolds had been seeded, cell-seeded valves were conditioned in a low-flow $(500 \mathrm{~mL} / \mathrm{min})$, low-pressure $(25 / 10 \mathrm{~mm} \mathrm{Hg}$ at 100 beats/min) environment for 7 days before being removed, washed, and implanted into sheep. The seeding and conditioning protocols were tested and their success verified by histology and immunohistochemistry at each of these steps before the in vivo studies.

\section{Valve Conjugation}

An antihuman CD133 monoclonal antibody was prepared from the AC133.1 hybridoma line (ATCC, Manassas, Va) using a hollow-fiber unit with serum-free medium (SFM4MAB; Hyclone, Logan, Utah) as previously described. ${ }^{12}$ The antibody was purified with protein $\mathrm{G}$ cartridges and concentrated into a neutral $\mathrm{pH}$ saline. Conjugation of the gassterilized decellularized heart valve occured in 2 steps within 24 hours of implantation. First, the scaffold was activated with $N$-ethyl- $N^{\prime}-3$-(dimethylaminopropyl)carbodiimide $(0.19 \mathrm{~g} / 100 \mathrm{~mL}$ buffer); then the antibody $(5 \mathrm{mg} / \mathrm{mL}$ ) was added at a ratio of $500 \mu \mathrm{g} / \mathrm{mL}$ in $N$-hydroxy succinimide.

\section{Valve Replacement Procedure}

Sheep $(35-65 \mathrm{~kg})$ were premedicated with ketamine and glycopyrrolate, intubated, and anesthetized with isofluorane before placement of a central venous catheter. With mechanical ventilation, a left thoracotomy was performed, and after anticoagulation, normothermic right atrial-carotid artery cardiopulmonary bypass was established with a single-stage venous catheter, a peripheral arterial perfusion cannula (12F-16F), and a Capiox FX15 oxygenator (Terumo Cardiovascular Systems, Ann Arbor, Mich) with venous blood directly returned to the reservoir. The pulmonary artery was 
transversely incised and the native pulmonary valve leaflets were excised. The experimental valve conduit was sutured in place with continuous 5-0 polypropylene sutures and the animal weaned from the bypass circuit. After anastomotic hemostasis had been assured, the cannulas were removed, the incisions were closed, and the animal was allowed to recover. Antibiotics and analgesia were given systematically and the animals were maintained postoperatively for either 1 or 3 months.

\section{Tissue Harvest}

At the appropriate time postoperatively, the sheep were again prepared for surgery (as described earlier). The heart was dissected free from the chest wall and lungs, excised, and rinsed with saline. The construct was dissected free from the heart, and samples from the leaflets and pulmonary artery wall were taken for histologic, biochemical, and biomechanical testing. One leaflet each was used for biomechanical testing, biochemical analysis, and histologic sectioning.

\section{Histology}

Frozen sections were prepared using paraformaldehyde/glucose/ optimal cutting temperature embedding media and standard histologic techniques. Sections were stained with either hematoxylin and eosin (for general architecture) or Herovici stain for collagen formation. In addition, a series of immunohistochemical staining methods was employed using specific primary antibodies and methods well established in our laboratories. ${ }^{12}$ Immunostaining for CD31, von Willebrand factor (endothelial cells), and alpha-smooth muscle actin (interstitial cells) was used to evaluate expression patterns within the valve leaflets. Sections were also stained for matrix metalloproteinase-9 (MMP-9). Monoclonal antibodies (Santa Cruz, Santa Cruz, Calif) were used in all cases with appropriate serum controls and native sheep leaflets for positive controls.

\section{ECM Content}

Biochemical evaluation of the ECM was performed on 1 leaflet using established methods. ${ }^{13}$ In brief, sulfated glycosaminoglycans (GAGs) and collagen were determined using the Blyscan sulfated GAG assay kit (Biocolor Ltd, Carrickfergus, United Kingdom) and Sircol collagen assay kit (Biocolor), respectively. These kits used quantitative dye-binding methods to determine the total quantity of the respective ECM component in the sample.

\section{Biomechanical Testing}

One leaflet from each sheep was tested for biomechanical characteristics using a uniaxial load test machine. Tensile strength testing was done at room temperature with a $100-\mathrm{N}$ load cell. Leaflet samples ( $3 \mathrm{~mm}$ width, full length) were prepared, attached at both ends to an atraumatic clamp, and subjected to uniaxial tensile loading to failure. Stress-strain relationships were compared between all groups to ensure maintenance of structural integrity.

\section{RESULTS}

\section{Surgical Implantation}

Eighteen animals were entered into the study with 16 completing the specified duration of implantation. One animal could not be weaned from bypass and never left the operating room. The second (conjugated group) died in the first postoperative week of non-cardiac related complications.

\section{Cell-Seeded Constructs}

EPCs were isolated from the circulation using the affinity column and grew to $2 \times 10^{6}$ cells within 12 days, expressing endothelial cell markers as previously reported. ${ }^{12}$ The porcine valves were successfully decellularized and contained no DNA material while maintaining their collagen and elastin architecture as previously described. ${ }^{11}$ After seeding and conditioning in the bioreactor, endothelial cells could be seen forming a confluent monolayer over $80 \%$ to $90 \%$ of the valve leaflets as previously reported. ${ }^{12}$

\section{CD133 Conjugated Constructs}

Conjugation took approximately 2 hours and the valves were implanted within 24 hours following the conjugation procedure. Five decellularized valves were conjugated with fluorescein isothiocyanate-labeled CD133 and placed in phosphate-buffered saline solution (with daily buffer changes) for 5 days. Daily, 1 valve was removed and examined for the presence of green fluorescence, indicating the continued presence of the coupled antibody. When present (out to day 4), fluorescence was concentrated on both leaflet surfaces but was also detected throughout its entire thickness (Figure 1). Three additional valves were conjugated with CD133-fluorescein isothiocyanate, placed in the bioreactor, and conditioned as described earlier. Valves were removed 1, 3, and 5 days after conditioning. All fluorescence was gone after 3 days (Figure 1).

\section{Valvular Cell Content}

Hematoxylin and eosin staining was used to assess cell content in the leaflets after 1 and 3 months in situ. After 1 month in vivo, cells were virtually nonexistent on unconjugated valve leaflets. Despite seeding with EPC-derived endothelial cells before implantation, cell-seeded valves did not display substantially more cells than the unconjugated controls. However, there was clear nuclear staining along the ventricular edge of the leaflet that extended through the lamina radialis into both the lamina spongiosa and fibrosa of conjugated valves. At 3 months, the results were nearly identical in both unconjugated and cell-seeded groups (Figure 2, A), whereas even more nuclei were distributed throughout the lamina spongiosa and fibrosa of conjugated valves. In addition to more nuclei, hematoxylin and eosin staining revealed an increase in eosinophilic staining throughout the spongiosa and fibrosa regions, likely owing to increased collagen.

To determine the distribution and density of cells in the conjugated valves, we used 4,6-diamino-2-phenylindole staining (Figure 2, B). Beginning as early as 1 week (determined in 1 animal that died of noncardiac complications), high densities of cells were observed along the edges of the leaflets. By 1 month, this had reached confluence along the ventricular side of the leaflet with increasing cell content across all lamina, but especially within the lamina fibrosa. At 3 months, all layers of the conjugated leaflets were cell-rich and densely populated. 


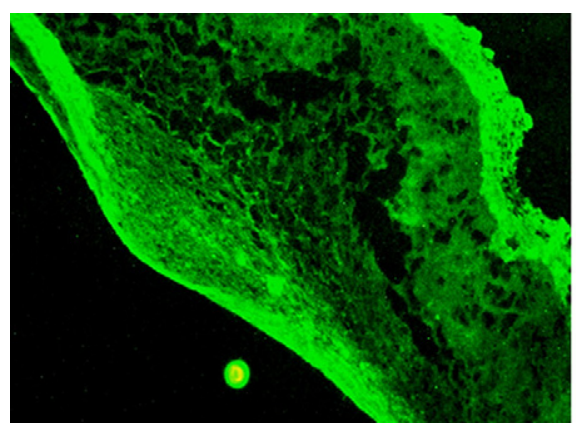

Two hours post-conjugation

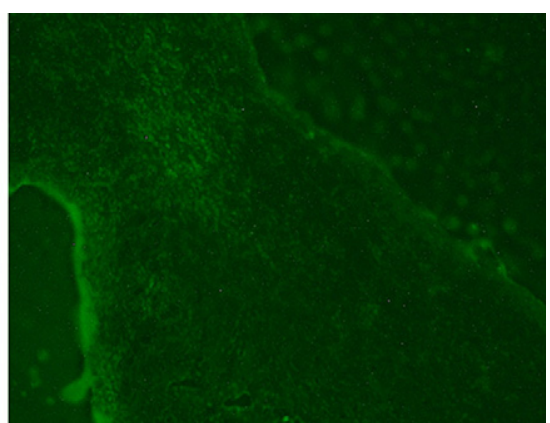

3 days post-bioreactor

FIGURE 1. Time course of antibody washout. Fluorescein isothiocyanate-labeled CD133 antibodies were conjugated to decellularized pulmonary valve constructs before being washed statically (not shown) or in a bioreactor for 3 days. Immediately after conjugation, intense fluorescence identified densely conjugated antibodies throughout the leaflet surface and lamina. After 3 days in the bioreactor, fluorescent intensity was reduced but not completely absent, suggesting that some antibody remains available to attract cells for at least 3 days after implantation.

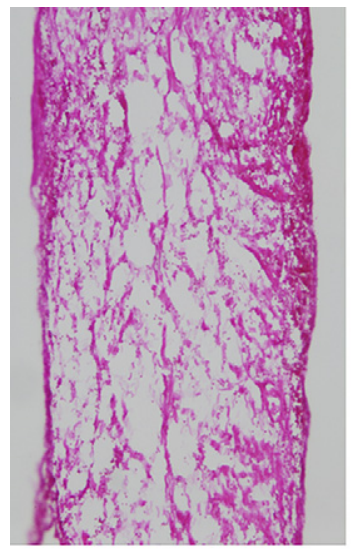

A

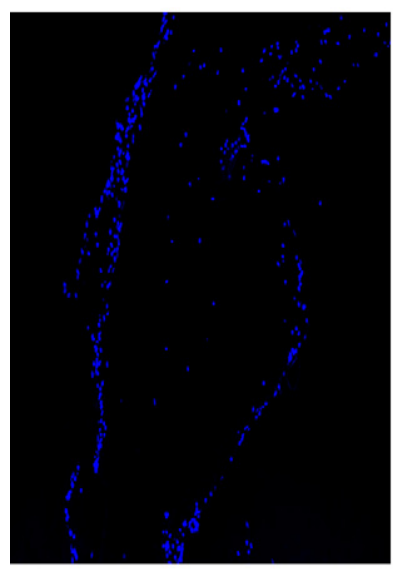

1-Week

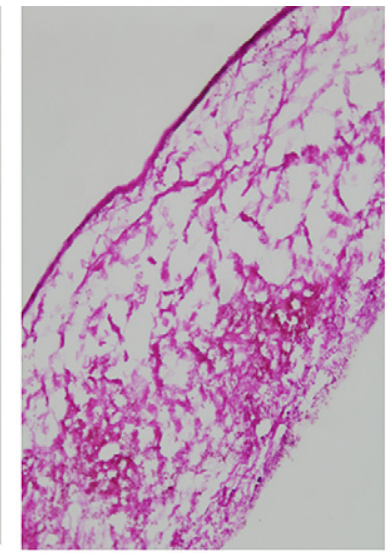

Cell-Seeded

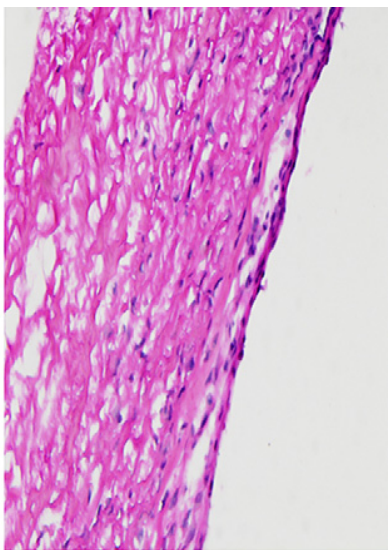

CD133 - Conjugated

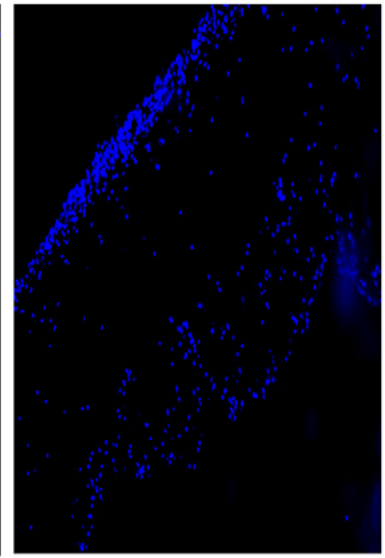

1-Month

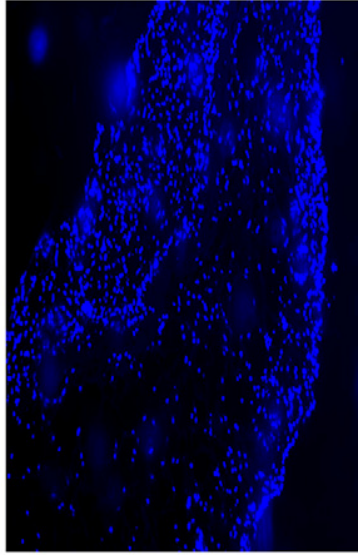

3-Months

\section{B}

FIGURE 2. A, Cell content after 3 months in vivo. Hematoxylin and eosin staining of valve leaflets. Conjugated valves exhibited nuclear staining across the entire valve with a predominance of cells along the leaflet edge. Unconjugated and cell-seeded valves had no or few cells, which were limited to the edges. B, 4,6-Diamino-2-phenylindole staining of nuclei of conjugated valve leaflets after 1 week, 1 month, and 3 months in vivo. Conjugated leaflets exhibited a progressive recellularization across the entire leaflet. 


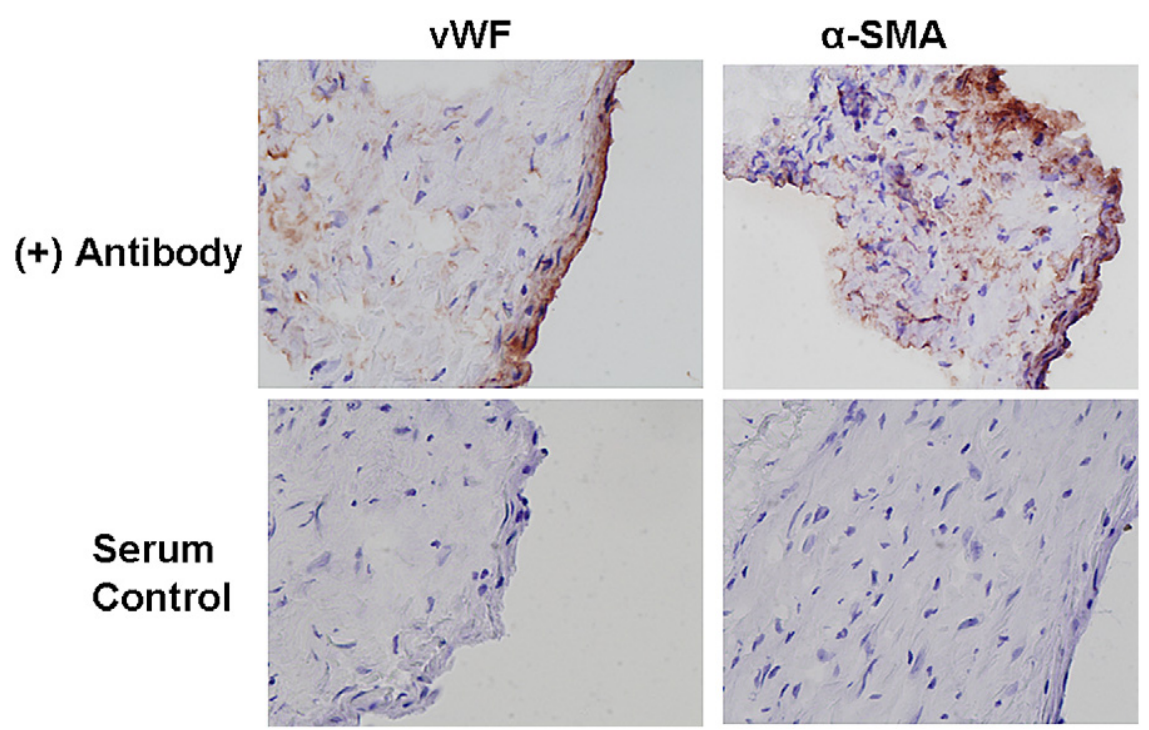

FIGURE 3. Cell types in conjugated leaflets after 3 months in vivo. Conjugated leaflets show specific staining for the endothelial cell marker, von Willebrand factor $(v W F)$, predominantly along the surface of the leaflet where endothelial cells would congregate. Similarly, though more widespread, conjugated leaflets exhibit specific staining for the interstitial cell marker alpha-smooth muscle actin $(\alpha-S M A)$.

Immunohistochemical techniques were used to determine the types of cells distributed throughout the conjugated valve leaflets. Figure 3 illustrates a predominance of von Willebrand factor-positive cells along the edge of the leaflets where endothelial cells are expected to reside. Furthermore, antibodies directed against smooth muscle actin show a broader distribution with intense staining throughout the lamina of the leaflet, suggesting that these are valvular interstitial cells.

Together, these data suggest that conjugated valves quickly and efficiently "self-seed" when implanted into the body, whereas the unconjugated valves show little recellularization. Not only are these valves densely populated with cells, but multiple cell types have become differentially distributed across the leaflets. Both endothelial cells and interstitial cells have populated the leaflets of conjugated valves, appearing to have migrated to the appropriate anatomic location. Despite placing cells onto the construct before implantation, it appears that most of these cells were lost from the scaffold within the first month in the cellseeded group. The fate of these cells was undetermined, but their loss is likely the result of detachment from the scaffold.

\section{Valvular Maturation and Remodeling}

Although cells of the correct phenotype are important, these cells must be functional to mimic native valves. New collagen formation was qualitatively assessed using Herovici stain. Figure 4, A, compares new collagen (blue staining) production in the 3 groups after 3 months in vivo. All 3 groups show development of new collagen fibers along the borders of the leaflets. However, there is little or no new collagen formation within the lamina fibrosa or spongiosa in either unconjugated or cell-seeded leaflets. In contrast, there is a widespread distribution of new collagen fibers in conjugated leaflets. This qualitative assessment was confirmed by a biochemical determination of acidsoluble collagen. Both unconjugated and cell-seeded valves exhibited a slight decrease in collagen content over time (Table 1), whereas conjugated valves significantly increased the collagen content from 1 to 3 months.

Similar to collagen, there was a decrease in the amount of sulfated GAGs over time in the unconjugated and cellseeded leaflets (Table 1). Again, conjugated valves exhibited an increase in sulfated GAG content at 3 months compared with the 1-month time point. Together, these data demonstrate production of matrix proteins by the cells attracted to the conjugated valve leaflets.

For remodeling to occur, not only do new matrix proteins need to be made, but older structural components must be removed. Figure 4, B, demonstrated the wide distribution of MMP-9 activity (brown staining) in the conjugated leaflets, suggesting that interstitial cells within the various lamina of the leaflet are using MMP-9 to break down structural proteins (collagen). In all, these data provide evidence that, in conjugated valves, the cells that have located to the leaflets are active participants in the maturation and remodeling of these leaflets. Such activity is missing in the unconjugated and cell-seeded valve leaflets.

\section{Biomechanical Properties}

Measurements of elasticity and tensile strength were assessed in the leaflets of all 3 groups. There were no discernible differences in either group or time related to the 


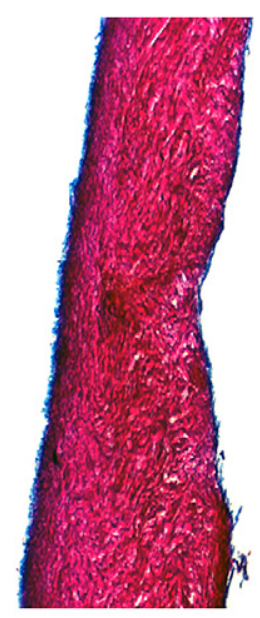

Un-Conjugated

A

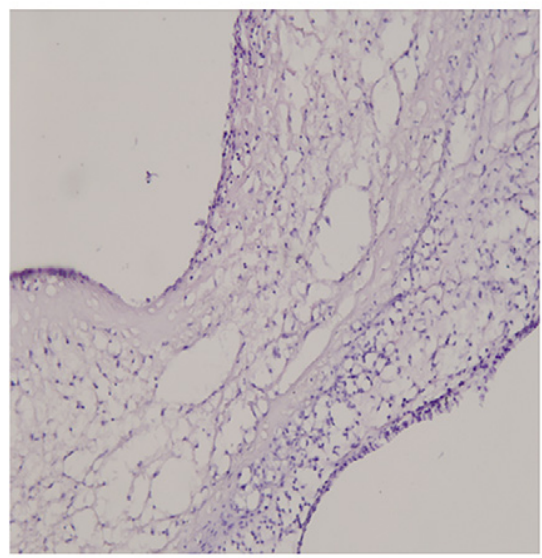

Un-conjugated

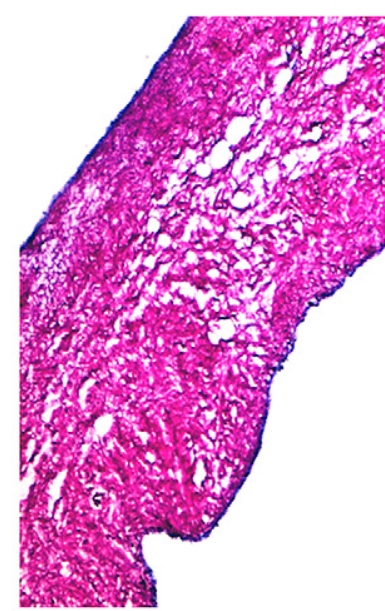

Cell-Seeded

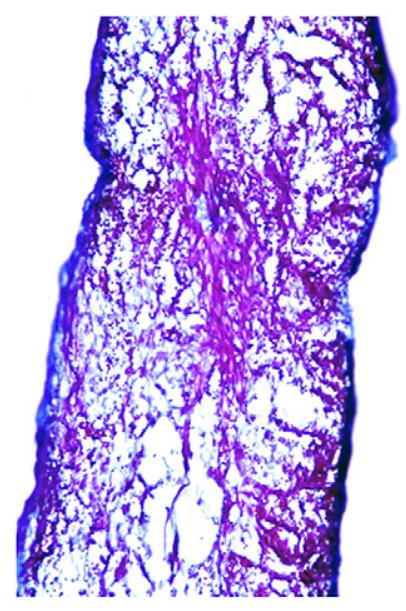

CD133-Conjugated

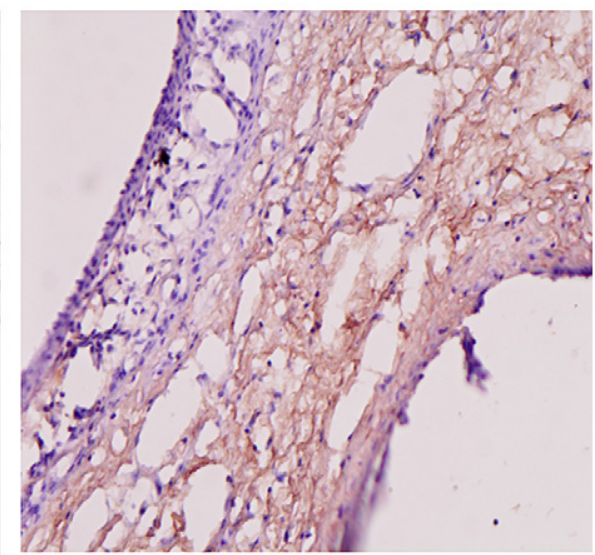

CD133-Conjugated

B

FIGURE 4. Formation and degradation of extracellular matrix (ECM) components. A, Using Herovici stain on sections of leaflets after 3 months in vivo, all groups exhibit signs of new collagen formation (blue staining). In unconjugated leaflets, this staining is limited solely to the leaflet edge whereas it is more widespread in the other groups. Conjugated valves clearly have the largest amount of new collagen formation at this time point. B, Remodeling requires both the production and degradation of the ECM. Here, matrix metalloproteinase-9 (MMP-9) activity is assessed using immunohistochemical techniques. Conjugated valves show widespread MMP-9 activity throughout the inner lamina of the leaflet. This activity is absent in unconjugated leaflets.

TABLE 1. Biochemical analysis of ECM components and biomechanical properties

\begin{tabular}{|c|c|c|c|c|}
\hline Experimental groups & $\begin{array}{c}\text { Acid-soluble } \\
\text { collagen }(\mu \mathrm{g} / 0 \mathrm{mg})\end{array}$ & $\begin{array}{l}\text { Sulfated GAGs } \\
\quad(\mu \mathrm{g} / 10 \mathrm{mg})\end{array}$ & $\begin{array}{c}\text { Young's modulus } \\
\text { (MPa) }\end{array}$ & $\begin{array}{l}\text { Tensile strength } \\
\text { at break (MPa) }\end{array}$ \\
\hline Normal pig valves $(\mathrm{n}=5)$ & $474 \pm 70$ & $52 \pm 7$ & $5.2 \pm 0.5$ & $3.0 \pm 0.3$ \\
\hline Unseeded, 1 mo $(\mathrm{n}=3)$ & $374 \pm 70$ & $52 \pm 7$ & $2.2 \pm 0.5$ & $1.0 \pm 0.3$ \\
\hline Unseeded, 3 mo $(\mathrm{n}=3)$ & $275 \pm 82$ & $22 \pm 5$ & $2.0 \pm 0.8$ & $1.5 \pm 0.2$ \\
\hline Cell seeded 1 mo $(\mathrm{n}=2)$ & $415 \pm 42$ & $44 \pm 10$ & $3.0 \pm 2.0$ & $1.0 \pm 1.0$ \\
\hline Cell seeded, 3 mo $(\mathrm{n}=2)$ & $370 \pm 50$ & $35 \pm 7$ & $3.0 \pm 1.0$ & $1.5 \pm 1.0$ \\
\hline Conjugated, 1 mo $(n=4)$ & $431 \pm 56$ & $45 \pm 9$ & $3.0 \pm 1.0$ & $2.5 \pm 0.5$ \\
\hline Conjugated, 3 mo $(n=4)$ & $587 \pm 72$ & $64 \pm 9$ & $6.0 \pm 2.0$ & $3.1 \pm 1.0$ \\
\hline
\end{tabular}

GAG, Glycosaminoglycan. 
tensile strength of the leaflets between unconjugated and cell-seeded valves (Table 1). The tensile strength of conjugated valves was elevated 1 month after implantation and continued to rise out to 3 months. However, this change in elasticity does not represent a large biological change.

\section{DISCUSSION}

The main findings of the study were as follows: (1) collecting, expanding, preseeding, and preconditioning valve constructs was a lengthy and challenging process; (2) the conjugation process was relatively quick and easy-conjugated CD133 remained on the scaffold for 3 days in a bioreactor, which may mimic its life expectancy in vivo; (3) conjugation produced a more cell-rich valve construct; (4) while functional remodeling was not assessed in this experiment, it appears that conjugated valves were producing the ECM and remodeling proteinases; (5) the biomechanical properties of conjugated valves were closer to those of normal valves than the other valve constructs.

Many efforts to create TEHVs have focused on scaffold material, culturing cells, and then using appropriate seeding and preconditioning protocols. ${ }^{14-18}$ Clinical use of these constructs began with isolated cases reported in the past decade ${ }^{19-21}$ using decellularized allografts seeded with autologous cultured endothelial cells. Follow-up (1-6 years) showed no mortality or significant morbidities, suggesting that TEHV may be a viable alternative to current valve technology. Others have reported on their early experience using autologous peripheral blood mononuclear cells in conjunction with a decellularized allograft matrix in pediatric patients. ${ }^{22}$ Peripheral blood mononuclear cells were differentiated directly on the valve scaffold for up to 3 weeks in a bioreactor before surgery. Follow-up occurred over 3.5 years with the TEHV showing excellent performance and hemodynamics with no signs of valvular stenosis, degeneration, cusp thickening, or decreased mobility. The authors even suggest that the valve grew with the patients. Larger clinical trials evaluating TEHVs are in their early stages. Dohmen and associates ${ }^{23}$ reported a series of 23 patients undergoing the Ross procedure who received a TEHV. In this study, decellularized grafts were seeded with autologous endothelial cells and cultured in a bioreactor. Follow-up showed no changes in mean flow velocities or regurgitation in the TEHV. Together, these results suggest that TEHVs may be feasible and safe with the potential to grow and remodel with younger patients.

The development of long-lasting, functional, and selfrepairing TEHVs depends on the cells that populate the construct and dictate the structural, functional, and remodeling processes of the valve. To this end, the valvular endothelial cells and valvular interstitial cells play a vital role in the health, function, and repair of the valve apparatus. The first hurdle to overcome is getting the proper cells to locate appropriately within the structure of the valve leaflets, with endothelial cells lining the edges and interstitial cells distributed throughout the lamina. Here we have demonstrated that conjugating an antibody against EPCs (CD133) to a decellularized valve construct, host cells can quickly repopulate the construct. Within 1 month, substantial cell accumulation had occurred along the edges of the leaflets, and by 3 months, cell density had increased throughout the leaflet. In our hands, this directed recellularization was far more efficient and effective than implantation of either decellularized valves (passive migration) or valves that were reseeded with endothelial cells before implantation. Although cell seeding did not prove effective in our hands, others have had more success, albeit with methods that require substantial time and effort. ${ }^{19-23}$

The potential of TEHV to remodel and grow with a patient, especially important in younger patients, was not directly assessed in this study. Interstitial cells are located throughout the valve leaflet and are tightly coupled to the ECM by forming new matrix proteins (collagen) as well as enzymes used to break down these structural components. ${ }^{24}$ These interstitial cells are quite active during development and may also be activated owing to injury or stress in adult tissues. Furthermore, the interaction between valvular interstitial cells and the ECM may play a role in the development of pathologic states such as calcification. ${ }^{25}$ Here we show evidence of valvular interstitial cell-like activity from cells positive for smooth muscle actin located throughout the various lamina of the valve leaflet. Conjugated valves had significantly elevated levels of collagen and GAG production, 2 important components of the ECM of valve leaflets. These data suggest an active participation of interstitial cells to remodel the decellularized graft and the potential for them to be involved in regulated construct growth and self-repair mechanisms over time.

The primary goal of the project was to demonstrate efficacy of in situ self-seeding valves and the ability of these constructs to remodel. Here, we focused on the histologic and cellular function of the cells populating the constructs. Also, in light of the large differences in the qualitative measures of cellularization and remodeling observed, coupled with the speed and ease of creating self-seeding TEHV, we determined that pursuing preseeded valves was not justified. Although there are limitations to this work, including length of study, lack of functional evaluation, and small numbers of animals studied, the data represent a proof-of-concept for the self-seeding TEHV. Thus, although the early time points examined are appropriate here, longer studies will need to be performed in the future. Similarly, valve function and durability will need to be examined as this work progresses.

\section{CONCLUSIONS}

On the basis of the data presented here, it may be unnecessary to culture, seed, and condition autologous cells on a scaffold to create a viable TEHV. By providing a means 
to attract endogenous cells to a viable scaffolding matrix, the time-consuming and technically demanding process of reseeding a valve construct may be bypassed. Conjugated valves have several other distinct advantages over autologous pre-cell-seeded valves. First, these constructs may be available quickly (within 24 hours), thus reducing the time until surgery can be scheduled. Second, these valves require no special handling techniques (either from the hospital or from the surgeon), thus facilitating their usage. Third, these valves may have the potential to grow with the patient, reducing the number of possible reinterventions experienced over a lifetime for those patients receiving them during childhood or early adulthood.

We thank Scott McGee, Wake Forest Baptist Medical Center Perfusion Services, and Ricquita Pollard for their contributions and technical abilities in support of this project.

\section{References}

1. Roger VL, Go AS, Lloyd-Jones DM, Adams RJ, Berry JD, Brown TM, et al. Heart disease and stroke statistics-2011 update: a report from the American Heart Association. Circulation. 2011;123:e18-209.

2. Lam CR, Aram HH, Munnell ER. An experimental study of aortic valve homografts. Surg Gynecol Obstet. 1952;94:129-35.

3. Vesey JM, Otto CM. Complications of prosthetic heart valves. Curr Cardiol Rep. 2004;6:106-11.

4. Senthilnathan V, Treasure T, Grunkemeier G, Starr A. Heart valves: which is the best choice? Cardiovasc Surg. 1999;7:393-7.

5. Sacks MS, Enomoto Y, Graybill JR, Merryman WD, Zeeshan A, Yoganathan AP, et al. In-vivo dynamic deformation of the mitral valve anterior leaflet. Ann Thorac Surg. 2006;82:1369-77.

6. Hoerstrup SP, Sodian R, Daebritz S, Wang J, Bacha EA, Martin DP, et al. Functional living trileaflet heart valves grown in vitro. Circulation. 2000;102(19 Suppl. 3):III44-9.

7. Stock UA, Vacanti JP, Mayer JE Jr, Wahlers T. Tissue engineering of heart valves-current aspects. Thorac Cardiovasc Surg. 2002;50:184-93.

8. Elkins RC, Dawson PE, Goldstein S, Walsh SP, Black KS. Decellularized human valve allografts. Ann Thorac Surg. 2001;71(5 Suppl):S428-32.

9. Simon P, Kasimir MT, Seebacher G, Weigel G, Ullrich R, Salzer-Muhar U, et al. Early failure of the tissue engineered porcine heart valve SYNERGRAFT in pediatric patients. Eur J Cardiothorac Surg. 2003;23:1002-6.
10. Engelmayr GC Jr, Sales VL, Mayer JE Jr, Sacks MS. Cyclic flexure and laminar flow synergistically accelerate mesenchymal stem cell-mediated engineered tissue formation: implications for engineered heart valve tissues. Biomaterials. 2006;27:6083-95.

11. Lee DJ, Steen J, Jordan JE, Kincaid EH, Kon ND, Atala A, et al. Endothelialization of heart valve matrix using a computer-assisted pulsatile bioreactor. Tissue Eng Part A. 2009; 15:807-14.

12. Tillman BW, Yazdani SK, Geary RL, Corriere MA, Atala A, Yoo JJ. Efficient recovery of endothelial progenitors for clinical translation. Tissue Eng Part C Methods. 2009; 15:213-21.

13. Balachandran K, Konduri S, Sucosky P, Jo H, Yoganathan AP. An ex vivo study of the biological properties of porcine aortic valves in response to circumferential cyclic stretch. Ann Biomed Eng. 2006;34:1655-65.

14. Berry JL, Steen JA, Koudy WJ, Jordan JE, Atala A, Yoo JJ. Bioreactors for development of tissue engineered heart valves. Ann Biomed Eng. 2010;38: 3272-9.

15. Dainese L, Biglioli P. Human or animal homograft: could they have a future as a biological scaffold for engineered heart valves? J Cardiovasc Surg (Torino). 2010;51:449-56.

16. Hjortnaes J, Bouten CV, Van Herwerden LA, Grundeman PF, Kluin J. Translating autologous heart valve tissue engineering from bench to bed. Tissue Eng Part B Rev. 2009;15:307-17.

17. Sacks MS, Schoen FJ, Mayer JE. Bioengineering challenges for heart valve tissue engineering. Annu Rev Biomed Eng. 2009;11:289-313.

18. Migneco F, Hollister SJ, Birla RK. Tissue-engineered heart valve prostheses: "state of the heart. Regen Med. 2008:3:399-419.

19. Dohmen PM, Lembcke A, Hotz H, Kivelitz D, Konertz WF. Ross operation with a tissue-engineered heart valve. Ann Thorac Surg. 2002;74:1438-42.

20. Dohmen PM, Hauptmann S, Terytze A, Konertz WF. In-vivo repopularization of a tissue-engineered heart valve in a human subject. J Heart Valve Dis. 2007;16: 447-9.

21. Gabbieri D, Dohmen PM, Linneweber J, Lembcke A, Braun JP, Konertz W. Ross procedure with a tissue-engineered heart valve in complex congenital aortic valve disease. J Thorac Cardiovasc Surg. 2007;133:1088-9.

22. Cebotari S, Lichtenberg A, Tudorache I, Hilfiker A, Mertsching H, Leyh R, et al. Clinical application of tissue engineered human heart valves using autologous progenitor cells. Circulation. 2006;114(1 Suppl):I132-7.

23. Dohmen PM, Lembcke A, Holinski S, Kivelitz D, Braun JP, Pruss A, et al. Midterm clinical results using a tissue-engineered pulmonary valve to reconstruct the right ventricular outflow tract during the Ross procedure. Ann Thorac Surg. 2007; 84:729-36.

24. Schoen FJ. Evolving concepts of cardiac valve dynamics: the continuum of development, functional structure, pathobiology, and tissue engineering. Circulation. 2008;118:1864-80.

25. Rodriguez KJ, Masters KS. Regulation of valvular interstitial cell calcification by components of the extracellular matrix. J Biomed Mater Res A. 2009;90: 1043-53. 